\title{
PENENTUAN STATUS GIZI BALITA BERBASIS WEB MENGGUNAKAN METODE Z-SCORE
}

\author{
Gunawan'), Ikhsan Nugraha Ash shofar ${ }^{2)}$ \\ Prodi. Teknik Informatika ${ }^{\text {1) 2) }}$ \\ Universitas Sangga Buana YPKP'), STMIK LPKIA ${ }^{2}$ ) \\ gunawan@ usbypkp.ac.id ${ }^{1)}$, shofar.ikhsan@ gmail.com²)
}

\begin{abstract}
ABSTRAK
Usia balita merupakan masa yang sangat spesial dalam proses pertumbuhan anak, periode ini menjadi awal dari serangkaian keberhasilan pertumbuhan anak pada tahapan berikutnya. Pertumbuhan anak pada usia balita adalah salah satu periode yang sangat spesial dan hanya akan terjadi sekali saja, Golden Age adalah istilah yang digunakan untuk anak usia balita. Pententuan status gizi balita dalam aplikasi ini menggunakan metode Z-score yang merupakan standar deviasi unit yang direkomendasikan oleh organisasi kesehatan dunia World Health Organizaion (WHO). Status Gizi yang akan dijadikan sebagai parameter adalah berat badan berdasarkan umur, tinggi badan berdasarkan umur, dan berat badan berdasarkan tinggi badan. Aplikasi ini akan dibangun dengan bahasa pemograman Java dengan bantuan spring boot framework, hibernate, dan MySQL sebagai databasenya. Pengunaan aplikasi ini khususnya oleh orang tua akan mempermudah dalam memantau pertumbuhan anaknya menjadi lebih baik.
\end{abstract}

Kata Kunci : status gizi, balita, z-score, java, framework, spring, hibernate

\section{PENDAhULUAN}

Masa balita adalah masa yang paling penting dalam siklus kehidupan, karena pada usia 0 sampai 5 tahun balita mengalami perkembangan fisik, mental dan perilaku. Oleh karena itu di usia tersebut balita perlu mendapatkan perhatian khusus dalam hal gizi mereka.

Tumbuh kembang anak di masa mendatang sangat dipengaruhi oleh perhatian orang tua dalam hala pemberian gizi di usia balita. Teknik penilaian terkait dengan status gizi balita merupakan cara yang secara kontinyu harus dilakukan agar kesehatan balita dapat terus terpantau dengan baik.

Pada saat ini untuk mengetahui status gizi balita, Posyandu menggunakan data dari antropometri. Antropometri adalah bidang ilmu terkait dengan ukuran dimensi bagian tubuh manusia seperti tinggi badan, berat badan, lingkar kepala serta dada dan bagian lain dari tubuh manusia.

Posyandu menggunakan Kartu Menuju Sehat (KMS) yang diisi setiap satu bulan sekali untuk memantau perkembangan status gizi balita. Kartu Menuju Sehat hanya digunakan untuk menentukan salah satu status gizi balita yaitu berat badan berdasarkan umur balita tersebut.

Untuk mengetahui status gizi yang lain, petugas posyandu dan orang tua harus mempunyai pengetahuan tentang metode z-score untuk membandingkan status gizi balita dengan data antropometri. Namun bagi petugas posyandu dan orang tua yang tidak memiliki pengetahuan tersebut akan mengalami kesuliatan dalam perhitungan dan cara mengetahui hasilnya.

Laporan seputar gizi dan kesehatan balita juga sangat dibutuhkan oleh pemerintah mulai dari tingkat desa sampai tingkat nasional untuk keperluan banyak hal seperti: sensus penduduk, pemberian bantuan untuk balita gizi buruk, pendataan balita untuk Pekan Imunisasi Nasional (PIN) dan pemetaan daerah tertinggal, karena tingkat kesejahteraan suatu daerah dapat dilihat dari status gizi balita di daerah tersebut.

Berdasarkan pembahasan diatas, maka pada penelitian ini akan dibuat aplikasi berbasis web yang dapat menentukan status gizi balita dengan menggunakan metode z-score berdasarkan data antropometri untuk mempermudah pemerintah, petugas posyandu dan orang tua dalam memantau status gizi balita. 


\subsection{Landasan Teori}

\subsubsection{Pengertian Balita}

Kata balita adalah istilah yang umum digunakan untuk usia anak hingga berusia 5 tahun. Pengelompokan usia anak 1 sampai dengan 3 tahun disebut dengan sebutan batita dan usia 3 sampai 5 tahun dengan sebutan pra sekolah.

Anak usia batita masih tergantung penuh dengan orang tua untuk setiap kegiatannya. Pada masa balita lah proses dimana pertumbuhan anak merupakan tahapan yang sangat penting, pada masa ini menjadi penentu agar pertumbuhan anak menjadi lebih baik pada periode berikutnya, the golden age adalah sebutan lain pada masa ini dan tidak akan pernah terulang lagi. (Sutomo \& Anggraini, 2010)

\subsubsection{Identifikasi Permasalahan}

1 Buku KMS hanya menunjukan salah satu status gizi balita, yaitu berat badan berdasarkan umur. Sedangkan masih ada beberapa status gizi balita berdasarkan data antropometri yang dapat memantau status gizi balita lebih jauh diantaranya berat dan tinggi dengan memperhatikan umur balita.

2 Kartu Menuju Sehat (KMS) sebagai alat untuk memantau status gizi balita dirasakan para orang tua masih belum cukup memberikan informasi yang dibutuhkan karena sering kali KMS hilang atau rusak.

3 Petugas Posyandu sering merasa kesulitan jika diminta untuk membuat laporan data balita secara mendadak untuk kebutuhan tertentu seperti Pekan Imunisasi Nasional (PIN).

\subsubsection{Ruang Lingkup Permasalahan}

1. Parameter yang akan digunakan dalam mengukur status gizi balita dalam aplikasi adalah berat badan berdasarkan umur, tinggi badan berdasarkan umur, dan berat badan berdasarkan tinggi badan.

2. Data yang digunakan untuk menguji perangkat lunak ini adalah data Posyandu Rw 03 Desa Tanjungsari Kecamatan Cangkuang Kabupaten Bandung Provinsi Jawa Barat.

3. Data Antropometri yang digunakan untuk menentukan status gizi balita adalah data antropometri yang dikeluarkan oleh Kementrian Kesehatan Republik Indonesia.
1. Membangun perangkat lunak berbasis web yang menunjukan status gizi lebih banyak dibandingkan KMS, status gizi yang akan ditampilkan antara lain berat badan, tinggi badan berdasarkan umur, dan berat badan sesuai dengan tinggi badan.

2. Memberikan informasi mengenai gizi balita kepada orang tua yang dapat diakses dimanapun dan kapanpun, tanpa khawatir alat untuk mendapatkan informasi tersebut rusak atau hilang seperti Kartu Menuju Sehat (KMS).

3. Membantu petugas Posyandu membuat laporan data balita.

\subsubsection{Pengertian Status Gizi}

Pengertian Status Gizi merupakan kondisi tubuh sebagai dampak mengkonsumsi makanan dan penggunaan zat gizi, dikelompokkan menjadi 3 kondisi, yaitu gizi kurang baik, baik, dan lebih (Almatsier, 2002).

\subsubsection{Pengertian Antropometri}

Antropometri adalah bidang ilmu terkait dengan pengukuran dimensi tubuh manusia lihat dari sudut pandang asupan gizi dan tingkatan umur. Beberapa parameter yang dapat digunakan untuk mengukur indikator status qizi adalah umur, berat badan, tinggi, lingkar kepala dan sebagainya.

\section{I.I.7 Pengertian Standar Deviasi atau Z-Score} "World Health Organization (WHO) menggunakan standar dalam mengukur dan memantau pertubuhan balita dengan menggunakan metode Z-score atau juga sering disebut standard deviasi unit" (Supariasa, 2001)

$$
Z-\text { score }=\frac{N I S-N M B R}{N S B R}
$$

Keterangan :

NIS : Nilai Individu Subyek

NMBR : Nilai Median Baku Rujukan

NSBR : Nilai Simpang Baku Rujukan

\subsubsection{Tujuan Perancangan}


Gambar 2 : Rancangan Halaman Login

\section{Analisis dan Perancangan}

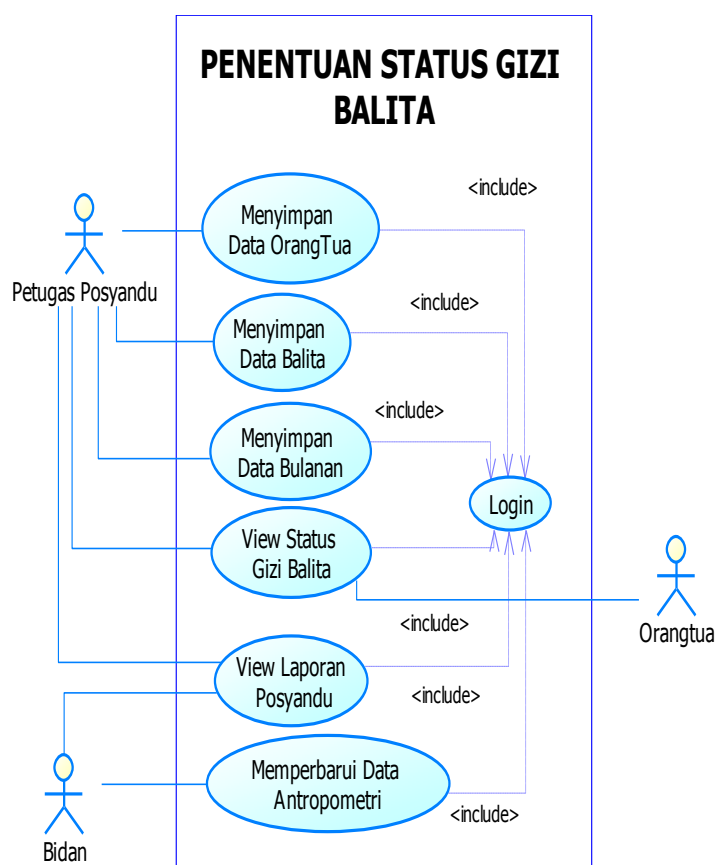

Gambar 1 : Usecase Diagram Penentuan Status Gizi

\subsection{Perancangan User Interface}

Perancangan user interface merupakan antar muka yang digunakan oleh user untuk berinteraksi dengan sistem. Antar muka yang dibuat sedapat mungkin dapat dengan mudah digunakan oleh user untuk mengoperasikan fungsionalitas sistem.

\subsubsection{Rancangan Halaman Login}

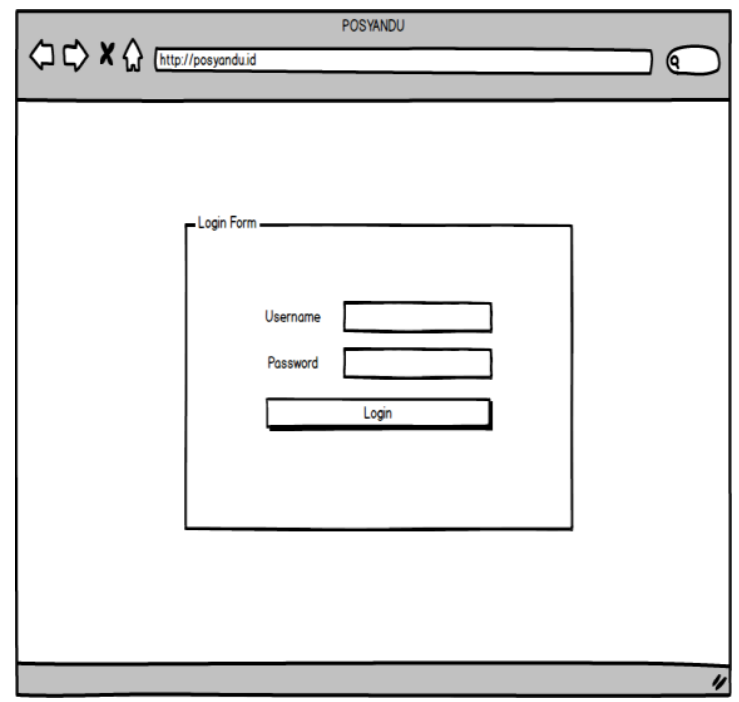

\subsubsection{Rancangan Halaman Tambah Balita}

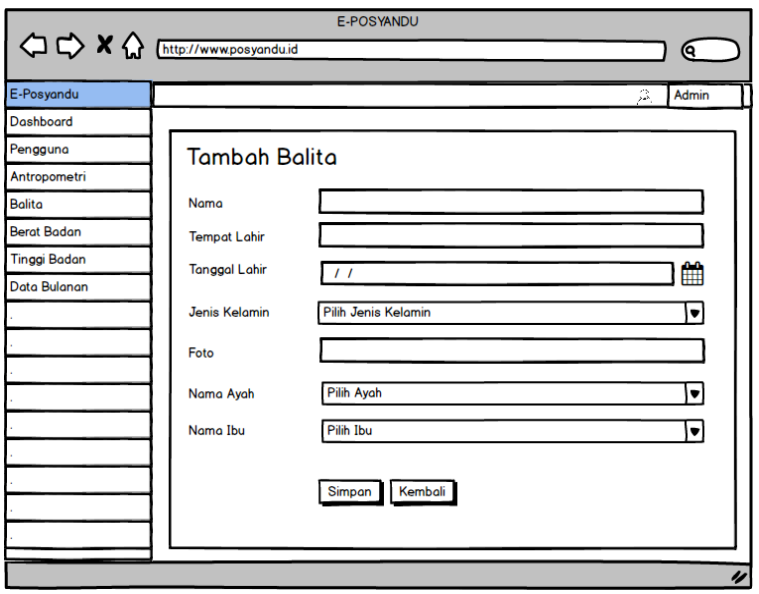

Gambar 3 : Rancangan Halaman Tambah Balita

\subsubsection{Rancangan Halaman Awal Data Bulanan}

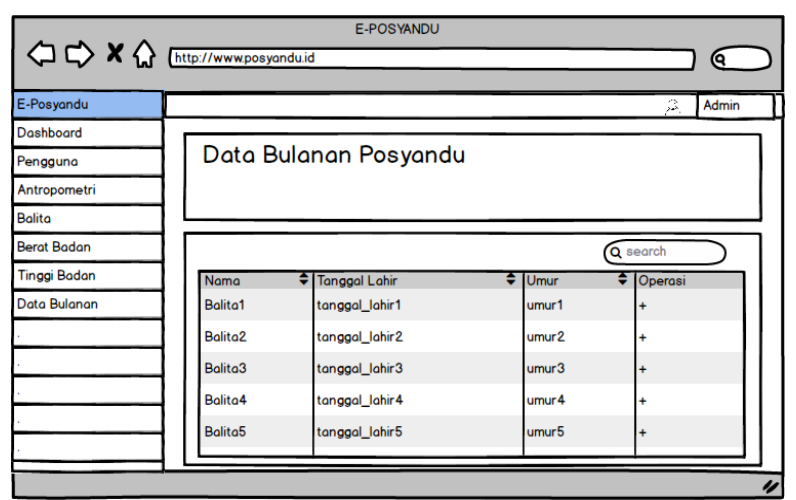

Gambar 4 : Rancangan Halaman Awal Data Bulanan

\subsubsection{Rancangan Halaman Profile Balita}

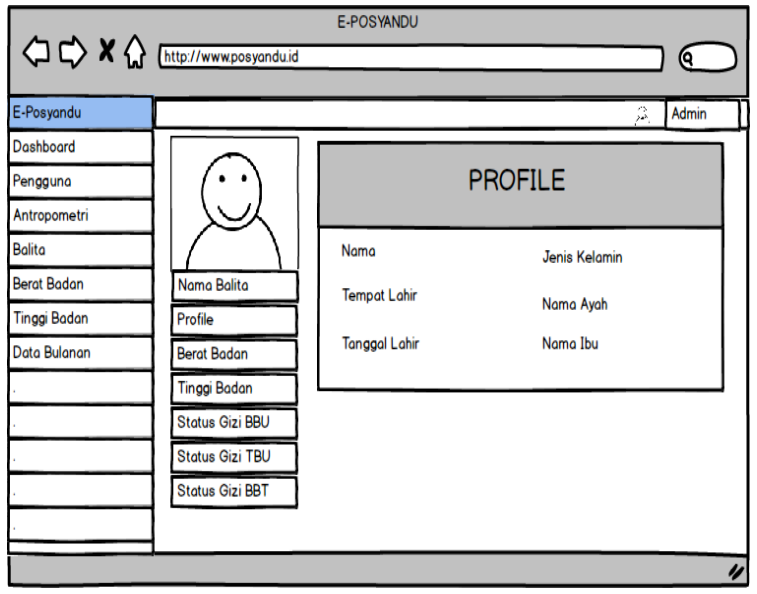

Gambar 5 : Rancangan Halaman Profile Balita 
2.1.5 Rancangan Halaman Berat Badan Balita

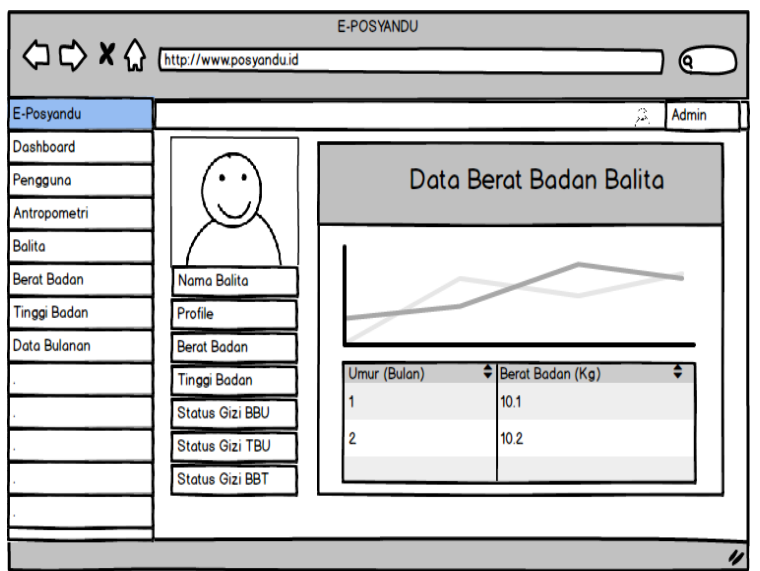

Gambar 6 : Rancangan Halaman List Menu Makan

\subsubsection{Rancangan Halaman Status Gizi Balita}

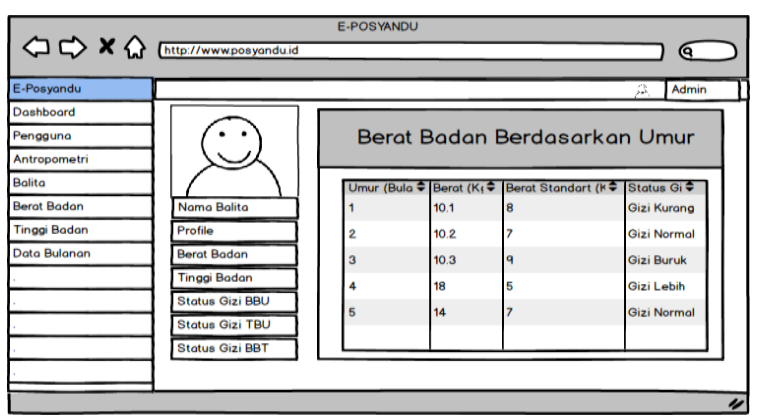

Gambar 7 : Rancangan Halaman Status Gizi Balita

\section{Implementasi}

\subsection{Deployment Diagram}

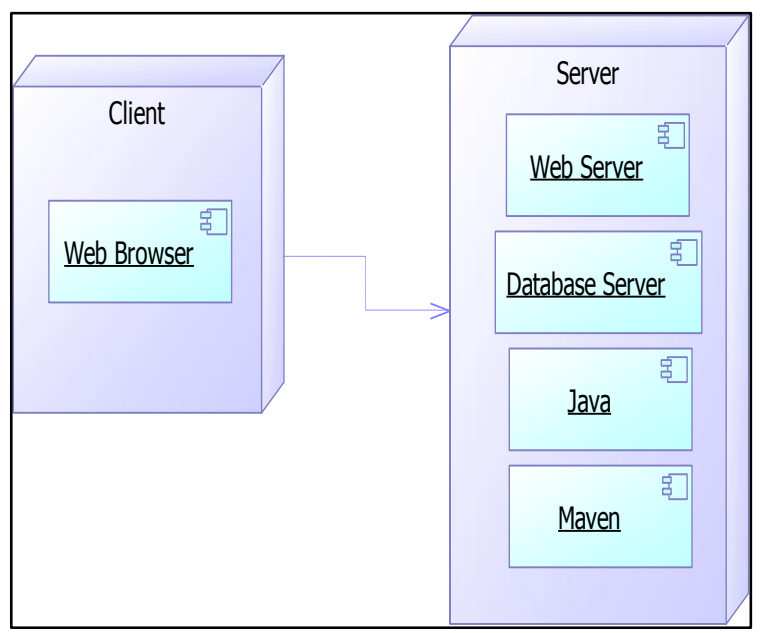

Gambar 10 : Deployment Diagram
3.3 Dialog Screen Login

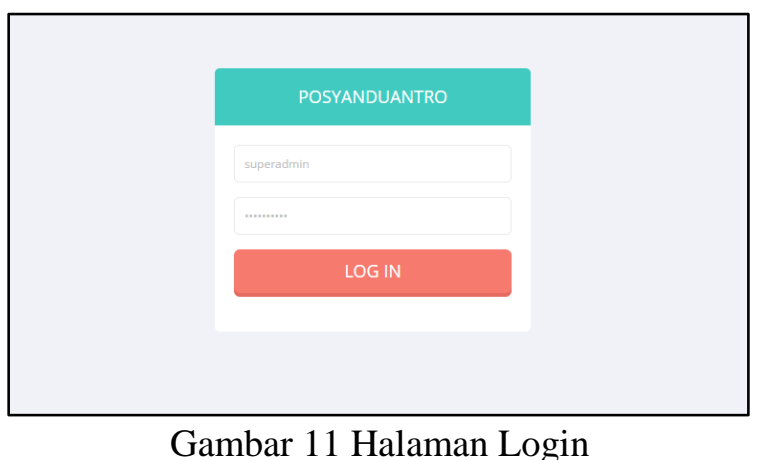

3.4 Dialog Screen Antarmuka Menu Orangtua

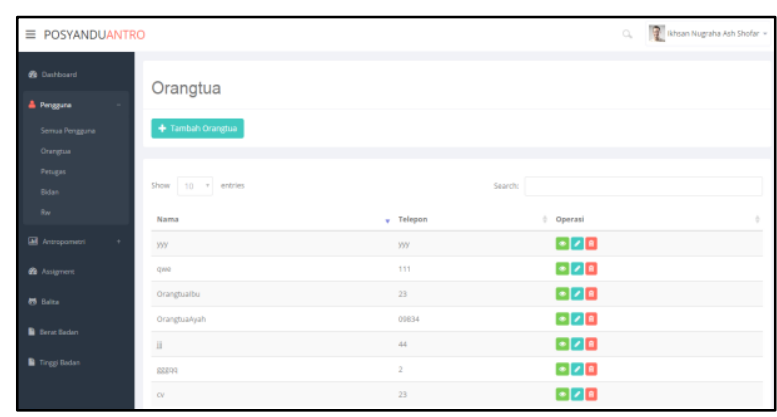

Gambar 12 : Halaman Antar Muka Menu Orangtua

\subsection{Dialog Screen Tambah Orangtua}
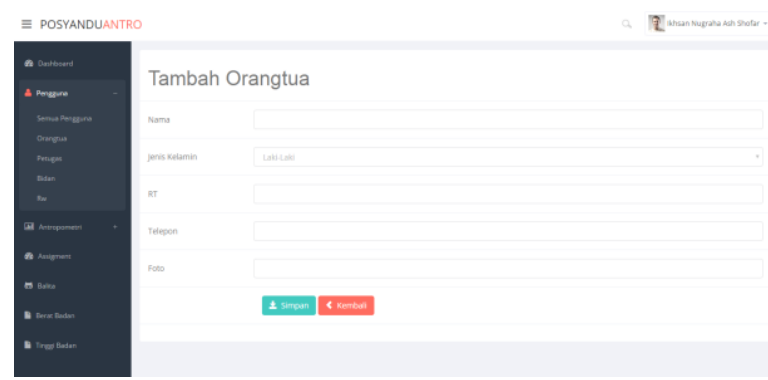

Tambah Orangtua

Gambar 13 : Halaman Tambah Orangtua

\subsection{Dialog Screen Halaman Awal Menu Balita}
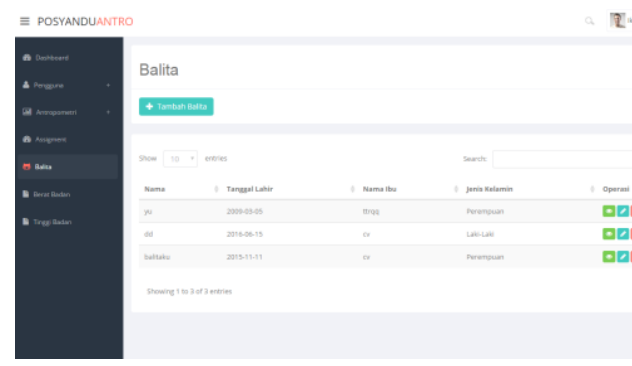

Gambar 14 : Halaman List Konsumen 


\subsection{Dialog Screen Tambah Balita}

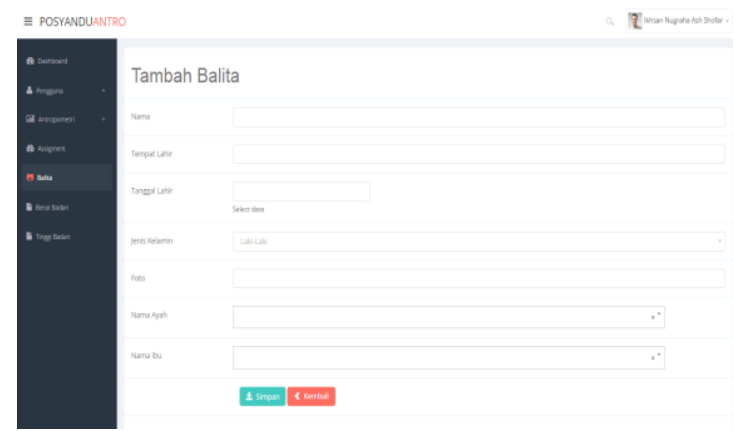

Gambar 15 : Halaman Tambah Balita

3.8 Dialog Screen Halaman menu data Bulanan

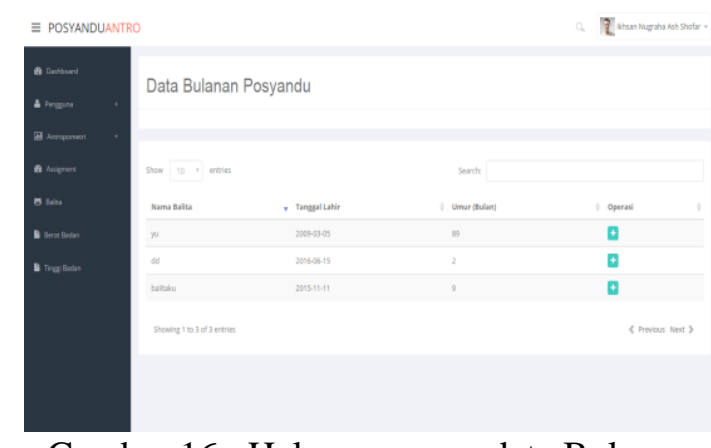

Gambar 16 : Halaman menu data Bulanan

\subsection{Dialog Screen Tambah Data Bulanan}

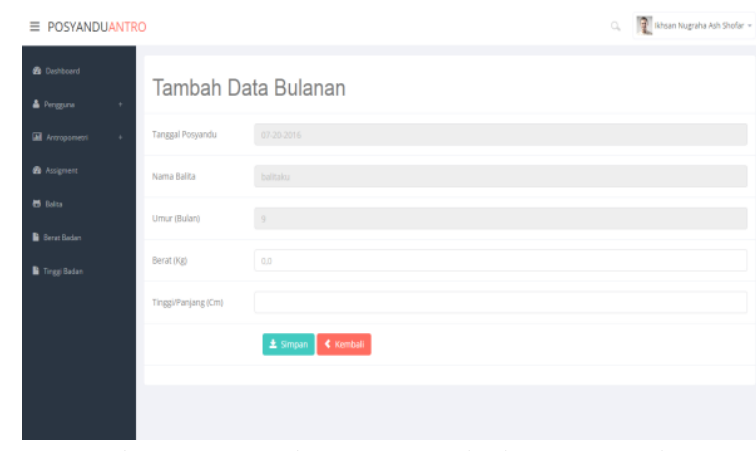

Gambar 17 : Halaman Tambah Data Bulanan

\subsection{Dialog Screen Halaman Awal menu Antropometri BBU}

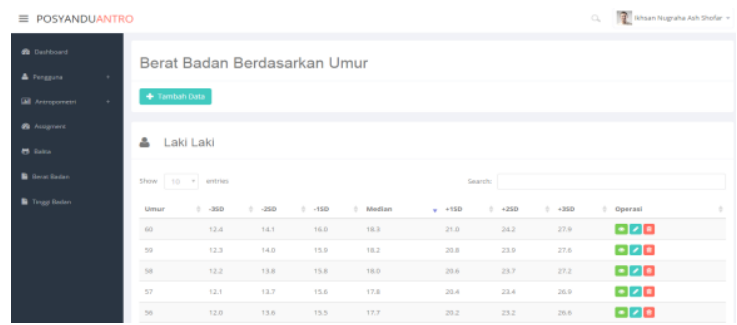

Gambar 18 : Halaman awal menu Antropometri BBU
3.11 Dialog Screen Edit Antropometri BBU

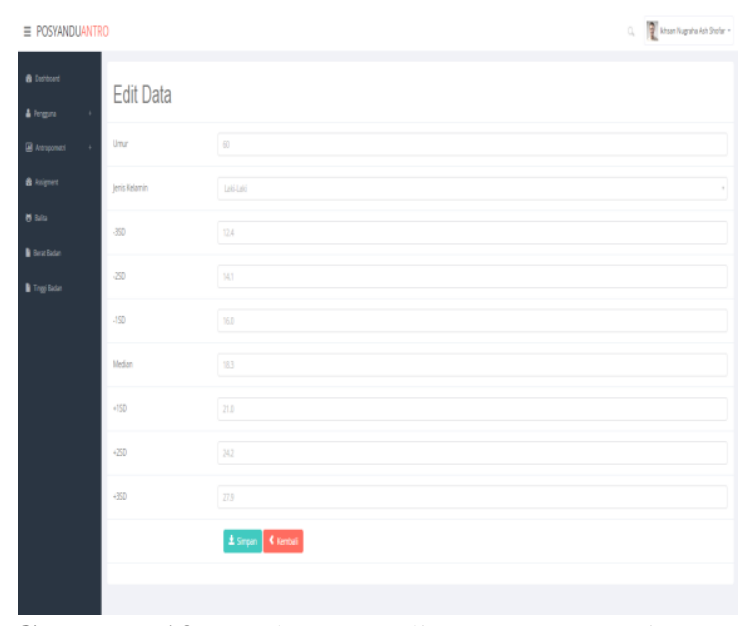

Gambar 19 : Halaman Edit Antropometri BBU

3.12 Dialog Screen Halaman Awal Profile Balita

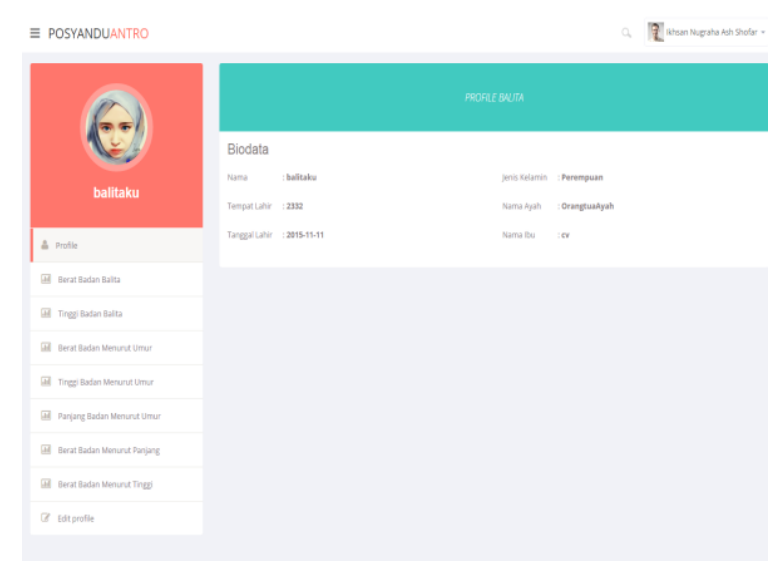

Gambar 20 : Halaman Awal Profile Balita

3.13 Dialog Screen Halaman Berat Balita

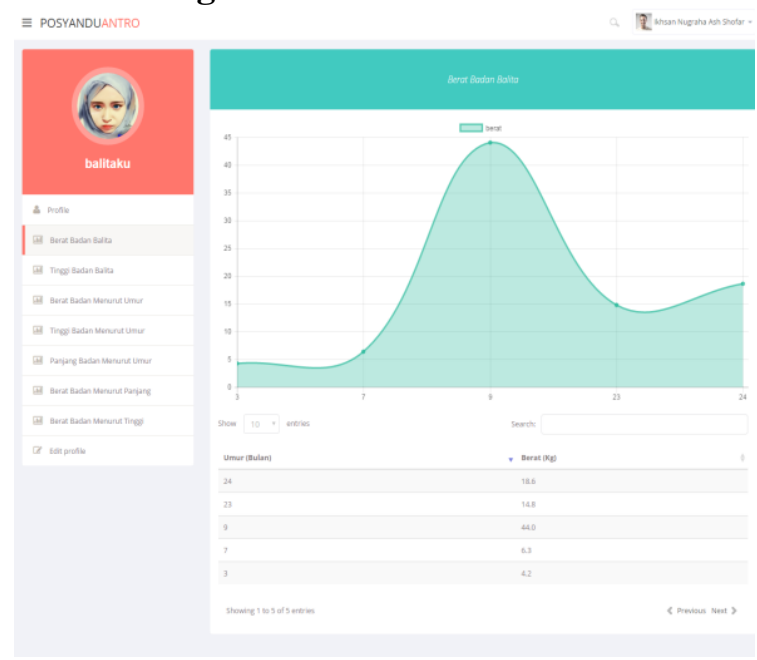

Gambar 22 : Halaman Berat Balita 


\subsection{Dialog Screen Status Gizi BBU}

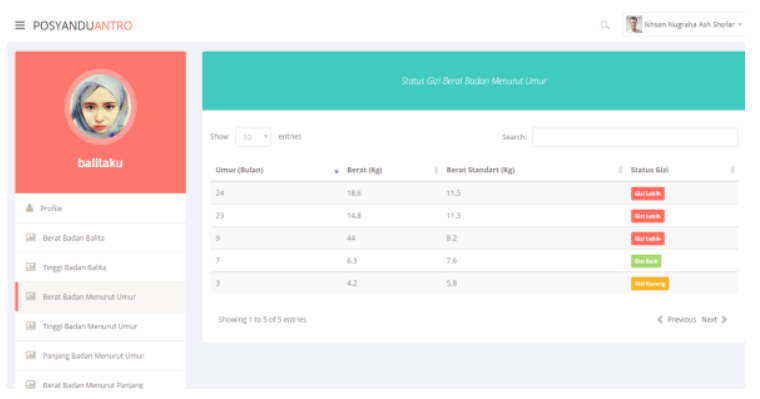

Gambar 23 : Halaman Status Gizi BBU

\section{Kesimpulan}

1. Dengan perangkat lunak penentuan status gizi ini orang tua dapat melihat status gizi yang lebih lengkap dibandingkan dengan status gizi yang ada di Kartu Menuju Sehat, status gizi tersebut adalah Berat Badan Berdasarkan Umur (BB/U), Tinggi Badan Berdasarkan Umur (TB/U), dan Berat Badan Berdasarkan Tinggi Badan.

2. Tidak seperti Kartu Menuju Sehat yang sering rusak atau hilang, orang tua dapat melihat status gizi anaknya melalui perangkat lunak ini tanpa takut rusak atau hilang.

3. Dengan perangkat lunak ini pertugas posyandu dapat membuat laporan yang berkaitan dengan balita menjadi lebih mudah.

\section{DAFTAR PUSTAKA}

[1] S., Rosa., \& Shalahuddin, M. (2013). Rekayasa Perangkat Lunak Terstruktur. Bandung: Informatika.

[2] Almatsier, S. (2002). Prinsip Dasar Ilmu Gizi. Jakarta: Gramedia Pustaka Utama.

[ 3 ] Aritonang. (2003). Pedoman Pemberian Makanan Pendamping ASI. Jakarta: Binarupa Aksara.

[4] Britton, C. (2000). Object-Oriented Systems Development. McGraw-Hill.

[5] Candra, B., Wahyudi, J., \& Hermawansyah. (2014). Pengembangan Sistem Kemanan Untuk Toko Online. Jurnal Media Infotama Vol. 11 No. 1, 31-40.
[ 6 ] Esterberg, K. (2002). Qualitative Methods in Social Research. New York: McGrow Hill.

[ 7 ] Moehji, S. (2002). Pemeliharaan Gizi Bayi dan Balita. Jakarta: Bhratara.

[ 8 ] Soekirman. (2000). Ilmu Gizi dan Aplikasinya untuk Keluarga dan. Jakarta: Direktorat Jenderal Pendidilan Nasional.

[9] Soetningsih. (1998). Tumbuh Kembang Anak. Jakarta: EGC.

[ 10 ] Supariasa, I., Bakri, B., \& Fajar, I. (2001). Penilaian Status Gizi. Jakarta: EGC.

[11] Sutanta, E. (2011). Basis Data Dalam Tinjauan Konseptual. Yogyakarta: Andi Offset.

[12] Sutomo, B., \& Anggraini, D. (2010). Menu Sehat Alami untuk Batita dan Balita. Jakarta: Demedia.

[ 13 ] Suyanto, A. H. (2009). Step by step web design theory and practices. Yogyakarta: Andi Ofset.

[14] Uripi, V. (2004). Menu Sehat Untuk Balita. Jakarta: Puspa Swara.

[15 ] Wardhani, R., \& Yaqin, M. H. (2013). Game Dasar-Dasar Hukum Islam Dalam Kitab Mabadi'ul Fiqh Jilid I. Jurnal Teknika Vol. 5 No.2, 473-478.

[ 16] Warno. (2012). Pembelajaran Pemrograman Bahasa Java Dan Arti Keyword. Jurnal Komputer Volume 8 Nomor 1, 40. 